\title{
Relational Leadership: Promoting Lifelong Service and Meaningful Learning
}

\author{
Beth Teagarden Bair, Richard Bair \\ University of Miami, Florida, United States
}

\begin{abstract}
In 2015, a university in rural Maryland offered an undergraduate service-learning leadership course, which collaborated with a service-learning community of practice. This interdisciplinary leadership course initiated and sustained personal and critical reflection and social interactions by integrating Computer-Medicated Communication (CMC) technology through Blackboard to provide support to students as they interpreted their service experiences. The design of this study was to describe the perceptions of the service-learning students' use of CMC technology to reflect on their service experience and social interactions within the service-learning community. In this descriptive case study, the in-depth content analyses of collected data from private journals and public discussions in Blackboard led to the distribution of a questionnaire to all participants and the execution of interviews regarding the participants' lived experiences. Once the participants responded, the researcher transcribed and assessed the results, coded emerging themes, and analyzed the trends. The triangulation of sources maintained the reliability of the findings, which demonstrated increased student engagement as result of social interactions and reflection in Blackboard. As the participants shared their lived experiences, they predominantly reflected on their personal growth and development, a strong community of practice, the value of relationships, and how technology enhanced their communication.
\end{abstract}

Keywords: Computer-Mediated Communication, online, relational leadership, service-learning, social constructivist theory

On today's university campuses, messages are often written on walkways because students are too engrossed in mobile technology to look up to read a sign. Likewise, in online learning courses, instructors frequently battle their old nemesis, student detachment. Nevertheless, one service-learning community and its instructor laugh in the face of disconnection to emerge fully engaged leaders from an online learning environment. Their secret formula is not found in a highly technological tool or a cryptic theoretical implementation, but rather in a foundational relationship, wherein all participants were fully invested.

\section{Social Constructivism}

Historically, learning has involved knowledge inside of an individual's head, but in a community of practice, the learning is found in the relationships between people (Murphy, 1999). As the individuals interact, the knowledge becomes more relevant because of the shared experience of the community. When students

Beth Teagarden Bair, Dr., Assistant Director, Office of the Provost, University of Miami, Florida, United States.

Richard Bair, Dr., Associate Dean, Division of Continuing and International Education, University of Miami, Florida, United States. 
stimulate one another to grow academically, the memory of important terms and concepts is stronger, and real learning emerges from this memory and relevance for the students (McDonald, Bowman, \& Brayko, 2013). The learning then belongs to the conversations in which the individuals, including the instructor, participate rather than the individuals themselves.

The bond in a service-learning community aligns with Vygotsky's social constructivism, where students learn by observing more experienced professionals and then modeling that behavior (Davis, 2013). Although both instructor and student bring their prior knowledge to the course, Hughes, Bradford, and Likens (2018) explained that learning evolves from the interpretation of their lived experiences through reflection and interaction. The service-learning literature also indicates several obstacles exist, which involve reduced class time and the balance of service and academics (Larkin \& Beatson, 2014). Thus, the instructors seek to develop relationships and technology tools for learning regardless of the reduced class time, which is necessary to permit adequate time for the students to complete their site service assignments.

When students have a strong connection with the course materials and other students, greater learning can occur (Smirnova, Rebiazina, \& Khomich, 2017). The students not only benefit from developing relationships with other learners, but they also grow from the reflection activities (Hughes et al., 2018). In the social constructivist approach to learning, the instructor provides important opportunities for student reflection to allow time for discovery and growth (Hoskins, 1995). Another crucial component is the involvement of the instructor, not only in the discussion of concepts but also in establishing trusting relationships with the students, as they share their hopes and dreams (George, 2008).

\section{Community of Practice}

In the change model of service-learning, the learning is focused on change rather than charity, equipping students to be more civically engaged (Kahne \& Westheimer, 1996). As students strive to meet the needs of their community, they learn to develop relationships with the individuals they serve as well as their community partners (McDonald et al., 2013). As these relationships deepen, the students grow in their understanding of others and the contexts in which they live. Because of the growing relationships, the students begin to care about their community and in their desire to improve it.

Some argue that the term "service" is inappropriate because it implies a negative inequality among the participants, but Dubinsky (2001) defended that the service-learning community should wear the mantle of service proudly because of the emphasis on caring relationships. The students build lasting connections, which helps them shift from a self-oriented to an other-oriented focus as they progress through college and eventually into the workplace (Dubinsky, 2001). By learning how to accomplish for the common good, students understand how to bridge theory and practice by applying their knowledge to help others, and in so doing, become educated citizens who actively serve their communities (McDonald et al., 2013).

Furthermore, instructors must also model social responsibility as they cultivate a community of learners who care about the subject matter as well as each other (Anderson \& Simpson, 2007). When the instructors model the standards of excellence for the students and devote themselves to their students and the passion of knowledge, the students understand the importance of integrity and relationships. George (2008) explained that this "capacity to develop close and enduring relationships is one mark of a leader... The rewards of these relationships, both tangible and intangible, are long lasting" (p. 96). 


\section{Purpose and Rationale of the Study}

The design of this study was to describe the perceptions of the service-learning students' use of Computer-Medicated Communication (CMC) technology to reflect on their service experience and social interactions within the service-learning community. To investigate student engagement, this study explored the participants' personal and critical reflections, social interactions, and course learning through CMC technology. Because of the descriptive nature of this case study, the researchers considered the participants' words and the content of their responses to determine student engagement.

\section{Significance of the Study}

For many course designers, incorporating the service-learning experience into an academic course can be difficult. Often the instructor reduces the time of face-to-face sessions to allow for the additional hours for service, but this situation can then reduce the time that students might interact with each other and the instructor to build community (Mills, 2001). Thus, some courses are integrating CMC to encourage conversations and support. These CMC's allow students to connect regardless of time and distance to discuss experiences from their service or their course work (Bonk \& King, 1998). This interaction suggests that the progression of CMC's coincides with instructional strategies for reflection, collective knowledge construction, and validation.

\section{Theoretical Framework}

To appropriately explore the students' perceptions within the service-learning community, the researchers chose to implement a descriptive case study, involving qualitative data collection strategies. The triangulation of archived student reflections in journals and discussion board postings, questionnaires, and interviews emphasized the participants' perspectives as a significant part of the research (Creswell, 2005). Then, the qualitative data collection advanced the interpretation of data to reveal themes and patterns regarding the participants' lived experiences (Yin, 2009). Because the focus of this study involved a contemporary phenomenon in a real-life context, the preferred case study method described and explained the ensuing events (Yin, 2009). As both the students and the community developed, the learning and the relationships flourished.

The need for support in a service-learning community aligns with the social constructivist theory on the significance of interaction as the means for knowledge construction and collegial relationship building (Al-Ansari, 2003). When students discuss their thoughts, they seek to make sense of knowledge in light of their experiences and begin to validate their learning with community support. In the cognitive process, the students integrate this new information into their prior stock of knowledge (Vygotsky, 1978). Although both instructor and student bring their prior knowledge to the course, Schubert (1995) explained that learning evolves from the interpretation of their lived experiences.

John Dewey (1938) envisioned education as a social activity as well as an experiential pedagogy. He deemed experience as not only important but necessary for learning to take place. He explained that as students interact with others in a learning environment, they construct new meaning and build knowledge in the process. As opposed to the traditional classroom, the constructivist learning environment is student-centered, and the instructor is a facilitator to the learning process (Laird, 1985). Dewey further described the learning experience as one in which the students build on the knowledge they already have through meaningful contexts. In the service-learning experience, students participate in activities that address human and community needs together with structured opportunities intentionally designed to promote student learning and development (Jacoby, 1999). 
When service supplements traditional classroom activities with structured opportunities for experiential learning and critical reflection, students begin a cycle, based on Kolb's (1983) theory of experiential learning. In this cycle, the learners participate in concrete experiences, and then they reflect on those experiences. As the learners form new ideas based on this reflective thinking, they continue to test those new concepts in further concrete experiences (Becker, 2000). In social constructivism, the students actively engage in the learning as well as the instruction, which results in individual growth and meaningful knowledge (Borman, Hewes, Overman, \& Brown, 2003).

\section{Research Design}

The purpose of this study was to describe the perceptions of the service-learning students' use of CMC technology through Blackboard to reflect on their service experience and social interactions. Because this case study used various sources of data, it elaborates on the unique details of the program studied and the different views of the individuals in the study (Stake, 1995). As the researcher evaluates the programs, qualitative research allows in-depth investigation into the thoughts and feelings of the participants (Hawk, 2010). The case study method allows for an even deeper understanding of the lived experience of the participants and the programs.

According to Yin (1994), descriptive case studies describe an intervention and the real-life context in which it happened. While case studies can investigate a variety of situations, this case study was descriptive in nature because the researcher investigated the perceived social interactions of the service-learning community through CMC technology intervention. These researchers investigated the social interactions and student reflections through CMC technology, exceeding basic observation through the content analysis of both critical reflection and social interactions.

The case study researchers developed a multi-perspective analysis for the allotted time frame and concentrated on minimum issues and minimum participants to ensure that the investigation was more streamlined (Hawk, 2010). In this intensive research, the researchers considered only the issues related to the lived experiences of the participants through CMC technology and only those participants in the specified service-learning leadership course. In order to confirm the validity of the case study, the researchers used the triangulation of multiple sources of data, establishing protocols that ensured accuracy and alternate explanations (Stake, 1995). In this case study design, the investigators extracted meaning from various sources to convey a clear interpretation of the phenomena of the lived experiences of the participants in this study, using common language from their backgrounds and prior knowledge. When the researchers compiled, analyzed, and triangulated multiple sources of data, multiple interpretations of perceptions and descriptions transpired, which enhanced the validity and reliability of the study. This case study represents the logical sequence connecting empirical data to the research questions and finally to conclusions (Yin, 2009).

\section{Data Source}

In this study, the triangulation of empirical data originated from a diverse group of students and their Blackboard artifacts, including reflective journals and discussion board postings, participant questionnaires, and participant interviews (see Figure 1). These identified sources offered insight into how the students perceived their service-learning experiences, as shown through the quality of the interactions, the indicators of a community of practice, and the nature of their critical reflections via CMC technology through Blackboard. 
With increased understanding of the lived experiences of the students in this study, the researchers focused on how the students made sense of their experiences and then transformed those experiences into their consciousness. The researchers meticulously, vigilantly, and conscientiously captured and described the lived experiences, including how the students remembered them, described them, and felt about the overall experience.

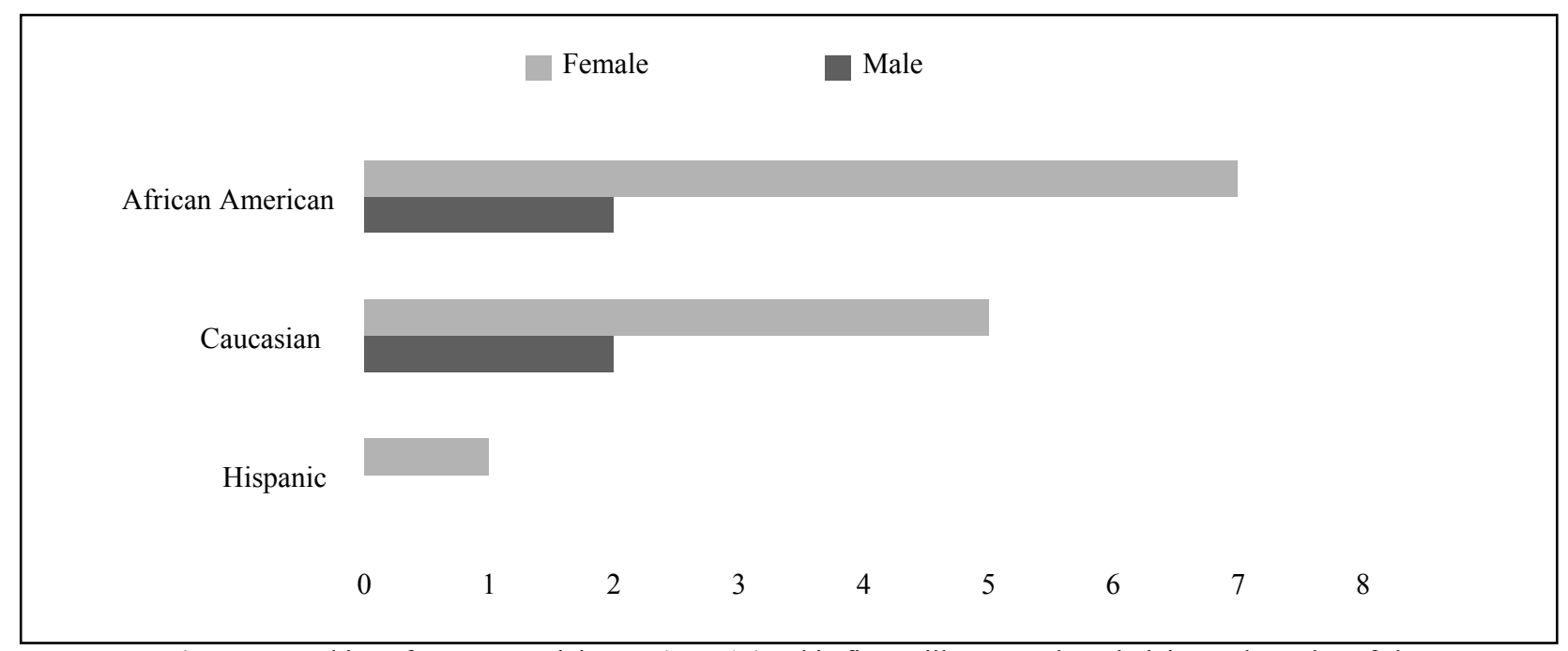

Figure 1. Demographics of course participants $(N=17)$. This figure illustrates the ethnicity and gender of the case study participants.

\section{Validity and Reliability}

Because the results are based on the lived experiences of the participants in the study, generalization is difficult, no matter how similar the programs and individuals may be (Hawk, 2010). For this reason, Yin (1994) introduced four applications for a case study model, which include explaining complex causal links in real-life interventions, describing real-life context in which intervention has occurred, describing the intervention, and exploring situations where the evaluated intervention has no clear set of outcomes. In this way, the case study allows the researcher to test already established generalizations. This study primarily involved the descriptive application because of the real-life context and the CMC technology intervention.

\section{Case Study Review}

To appropriately explore the students' perceptions of the use of technology to reflect within the service-learning community, the researchers chose to implement a descriptive case study, involving qualitative data collection strategies. As this case study explored the phenomenon of the lived experiences of this community, the observations of the relationships and interactions occurred through a reflective lens. The researchers used the students' own narratives to describe the role of interaction and reflection, as they conceptualized the lived service experiences to build knowledge and relationships. All names in this study are pseudonyms for the actual participants.

To allow for open sharing and private expression regarding the students' lived experiences, the researchers administered a questionnaire and distributed it to each participant of the service-learning course. The questionnaire consisted of unstructured and semi-structured questions and free responses to allow participants 
to discuss their perceptions and lived experiences without boundaries or limits. The questionnaire helped to keep the focus on the topic of the case study and provide important insight from the participants (Yin, 1994). Ten participants agreed to participate in the questionnaire, signed the consent form, and returned the completed questionnaire. The researchers coded their responses based on the established categories from the Blackboard documents as well as other themes or parent nodes that emerged as they responded. Based on these results, the researchers prepared the interview questions for the final component of the triangulation and for maintaining the descriptive case study's chain of evidence.

In order to understand the lived experiences of the service-learning students, the researchers also interviewed the participants regarding their experience. Eisner (1998) asserted that the interview process is a powerful resource to learn more about the participants' perceptions of their shared experiences. The interview also provided multiple views of the case for the researchers and the reader (Stake, 1995). To answer the research questions, the researchers interviewed seven students with both unstructured and semi-structured questions. These students agreed to participate in the interviews and signed the consent form. Through the participant interviews, the researchers investigated the students' perceptions of the social interactions within the $\mathrm{CMC}$ technology and their lived experiences. The interview questions also prompted the participants' reflection on their social connections within the community of practice.

While leading and serving at their service sites, the participants reflected on developing relationships and meaningful connections through CMC technology. One participant shared about a relationship with a child who needed help in learning English.

...Robert was a child from China, recently, and he was really smart, but...he didn't know some words. Like he knew what a cat was, but he didn't know what a kitten was. He knew what thunder was, but he didn't know what lightning was.... I'd read with him, and have him write down any of the words that he wasn't familiar with. So, and then by the end of the semester, he seemed pretty confident in the way that he spoke...

In his mentoring sessions with Robert, this participant cared about helping this child adjust to a new country and a new language. He considered the best approach to relate to him and help Robert succeed.

\section{Instructor Influence}

Within the community of practice, the members developed important relationships in their social interactions and their lived experiences. They discussed their desires to get to know each other, help others in need, and develop a strong community of practice. The participants elaborated on the professor, who was an important component in the community of practice. Unanimously, they agreed that the professor stood as a strong leader who provided the encouragement and feedback they needed in their service-learning experience. They recalled his feedback to their discussions and his approach to their input. One student shared,

There was always positive feedback. He wouldn't say, "You're completely wrong." Because if someone has an opinion about something, it's their opinion, but at the same time, he would let you see the perspective of another person. Or let you see the flaws in what you're saying or like what may go wrong when other people may not agree with you. He's an interesting person, and his ideas are also interesting.

Another participant discussed the interaction with the professor within Blackboard as well.

He would check Blackboard, and he would reply back, and we would go over things. I remember him writing down certain things in his notes, and we would go over them in class again. We knew he was looking at it and wasn't just like 
telling us to do it and then not looking at it or caring about it. He wasn't just checking to see that you completed it; he read them and wanted to talk about them.

This participant understood that the class assignments were valuable to the professor. He diligently replied and shared feedback to their postings and opinions.

Regarding this critical component of meaningful feedback, one student explained the instructor's interaction with the participants.

You could definitely tell that he cared about all of us, all of the students. He would always ask us how we're doing, and make sure we weren't doing badly. Or if we were, he would try to help us out. And then in the class, he would always try to help us figure out the answer ourselves. Like he would say things to help us figure out the answer.

In this way, the instructor developed a relationship with the students and became an active part of the community of practice via CMC technology in Blackboard.

Another participant elaborated on the impact of the professor's encouragement and feedback that they needed in their service-learning experience. They recalled his investment in their discussions and his approach to their input. One student explained the professor's teaching style and concern for his students.

Coming from high school to college, I thought it was nice to have a professor who cared. He helped us transition from topic to topic, and it was nice to have someone that you could go to talk to. He was comfortable instead of intimidating. There was no pressure. He teaches with open arms.

This description reflected the student's perspective of the instructor's genuine interest in the students and the example he set as a relational leader.

An additional student considered the relational ways that the professor modeled leadership and interacted with all of the students throughout the course as a valuable member of the community of practice.

Mr. Williams has high hopes for his students. He sees everyone around him excelling and succeeding and no one left behind. His hopes are that his students are actually understanding the impact of what's being taught and that they'll go off to accomplish great things just as he envisioned. He tries to get the students involved, you can see in his eyes that he's hopeful someone will raise their hand and their voice. Mr. William's hopes are quite wholesome.

In this excerpt, the participant described not only the instructor's involvement in the community of practice, but also his method of modeling service and relational leadership for the students.

Another student added insight into the relational leader and class discussions. "Mr. Williams was very motivating, able to relate to us. He let us talk and take ownership of the discussion. He was open to our responses and accepted everything we said". When describing the professor's facilitation of course discussions, one student shared, "What my interactions taught me about leadership was that when being a leader, you must realize everyone has different views and you must respect each and every one of them".

\section{Site Supervisor Influence}

This interaction and reflection prompted the students to recall the inspiration of other leaders, family members, and significant others. As all the participants reflected on their growth, they paid tribute to leaders who motivated them. These leaders modeled the standards of excellence and devoted themselves to their students and the passion of knowledge and service, and the service-learning students grew in understanding the importance of integrity and relationships (Anderson \& Simpson, 2007). One student shared about a service site supervisor who displayed a genuine interest in animals and humans alike at a local animal shelter. 
Although he is a great person to be around and work with, I think the most substantial reason why he has had such a positive impact on me is watching how he cares for all the animals. Whether it be cats or dogs, he has unconditional love for all of them. The way he interacts with the animals and never gets frustrated is really inspiring to me to do the most I can during my three-hour visit.

This participant perceived the site supervisor as one who emulated the important traits of an effective leader.

Another student shared insight into a service site supervisor who shared guidance as well as the rules for a healthy and safe environment at a local Young Men's Christian Association (YMCA).

Carla has been that someone who has made a positive impact on me so far while serving at the YMCA. Carla has helped us out so much by telling us the rules and she also let us know about some of the kids who have allergies to certain food which is very helpful. She also made it very clear that the kids need to get their homework done before they are allowed to play.... When we showed up to our service site, Carla introduced herself to all of us and the staff members that were there as well. They wanted to get to know us so well. Carla is such a wonderful woman and the work that she does for the kids is truly amazing.

In this excerpt, the participant explained that the site supervisor was careful to know the rules, but more importantly, the children themselves as well as the service-learning members who served there. She was a strong leader who demonstrated that she truly cared about the individuals at the YMCA.

Within the service-learning course, the participants perceived and developed important relationships which directly affected their learning through Blackboard. They discussed empathy and significant relationships in their desire to evolve as relational leaders, help others in need, and develop a shared culture.

\section{Personal Application}

In their reflections and discussions, the students displayed their growing knowledge of the relational leader and the importance of relationships in service. Within all of the artifacts, the researchers discovered that all participants expressed their understanding of relationships for themselves, the community, children, animals, and leaders. One student demonstrated an understanding of the relational leader and offered an example from a service site supervisor.

It is so valuable to be a relational leader so that you get the trust and respect of who you want to lead. You are valued because they understand you better. They view you as a human as well. To be a relational leader, you must know yourself and others around you, be open to differences and value different perspectives, and practice listening skills. Ms. Lynn is a wonderful person. She is able to talk with a soft voice and have the students understand her. They listen to her every word and obey her. She will participate with the children's games and ask them about their home life. She shows that she really actually cares about them as individuals. I strive to have this type of connection with the children. I am going into the profession of Education with the goal of Special Education. I want to be able to be a relational leader to my students in the future and Ms. Lynn shows it wonderfully.

In this passage, the participant explained the importance of a relational leader and further explained the qualities displayed so vividly by Ms. Lynn.

Another student witnessed a change in the children and shared the epiphany of a relational leader from that reflection.

These 2 young boys were not the brightest, or best behaved but they truly helped me to see my passion for teaching children! After working with [them] for a couple weeks I began to see a change in these 2 boys work habit, their confidence, and their overall attitude toward school. This had to be the most amazing thing I had ever experienced, 
knowing that you can have that much influence over youth opened my eyes to the idea that I can actually be a part of change!

As this student experienced the power of leadership, he/she determined to use that power for educating children in the vocation of teaching. The relationship that developed through this service experience changed the course of learning for the children as well as the participant.

\section{Conclusion}

The purpose of this study was to describe the perceptions of the service-learning students' use of CMC technology to reflect within the service-learning community. From Blackboard, the researchers collected 207 reflections from the journals and discussion board postings, and from subsequent individual submissions, they gathered 90 questionnaire responses, and 63 interview responses.

Once the data were assembled, the researchers began the process of coding the data through three intensive cycles. The first cycle involved an initial reading where themes or nodes emerged, and the researchers recorded the recurring themes or nodes in analytical memos. The second cycle included rereading the responses and applying values coding to the emerging themes or nodes. The third cycle comprised of entering the submissions into NVivo, where 26 overall themes or nodes emerged from the entries. The researchers then categorized them under four parent nodes or themes and subdivided them accordingly into child nodes. Overall, the researchers identified 1,887 references to the emerging nodes as they pertained to the research questions.

In their personal and critical reflections, the students revealed meaningful relationships and emotional connections with others at their service site. From these relationships, they expressed a desire to help others in need. The participants discussed emotional connections, shared culture, their shared passions, and especially relational leadership. In fact, the central theme of the value in relationships and the relational leader dominated their responses (see Figure 2). They specifically shared their appreciation for relational leadership and their desires to become relational leaders. From their conversations and private reflections, they described the valuable traits of a relational leader, and from those conversations, they learned more about the type of leader they presently were and hoped to become.

The participants not only experienced emotional connections and compassion, but they also developed as people in their understanding of their life goals. The participants brought a strong passion to their service sites, which led to reciprocal experiences for the students and the individuals they served (Farrell, 2014). In this way, they developed relationships with the individuals and the community they served. As they began to care about their community, they began to seek ways to improve it and help others gain life skills. In their lived experiences, the participants declared a lifetime commitment to service and remaining civically engaged in college and their careers (McDonald et al., 2013). As they grew in their knowledge of and desire for social change, they began to envision themselves as change agents.

Beyond their service experiences and course applications, the students reflected on their own personal growth and development. They described the motivation to overcome obstacles to healthy relationships and career passions. They shared their challenges to balance their academic and service responsibilities and include time for friends and recreation. The participants shared a clear understanding of their purpose in life and the critical skills for achieving their career and relational aspirations.

The evidence of community building supports Laird's (1985) research that the instructor in this community of practice was a facilitator in the learning process. He modeled social responsibility and cultivated 
a community of learners who cared about the course concepts and each other (Anderson \& Simpson, 2007). Because of his passion and leadership, the students understood and valued relationships. Since the instructor provided a visible framework for reflection, the participants shared their lived experiences and helped to generate rich discussions (Bleicher, Correia, \& Buchanan, 2006; Calkins \& Oxenhorn, 2005). From their reflections, the students displayed an understanding and often a mastery of social change and relational leadership. They expressed an appreciation for relational leadership and their desire to cultivate relationships in their service and their future achievements.

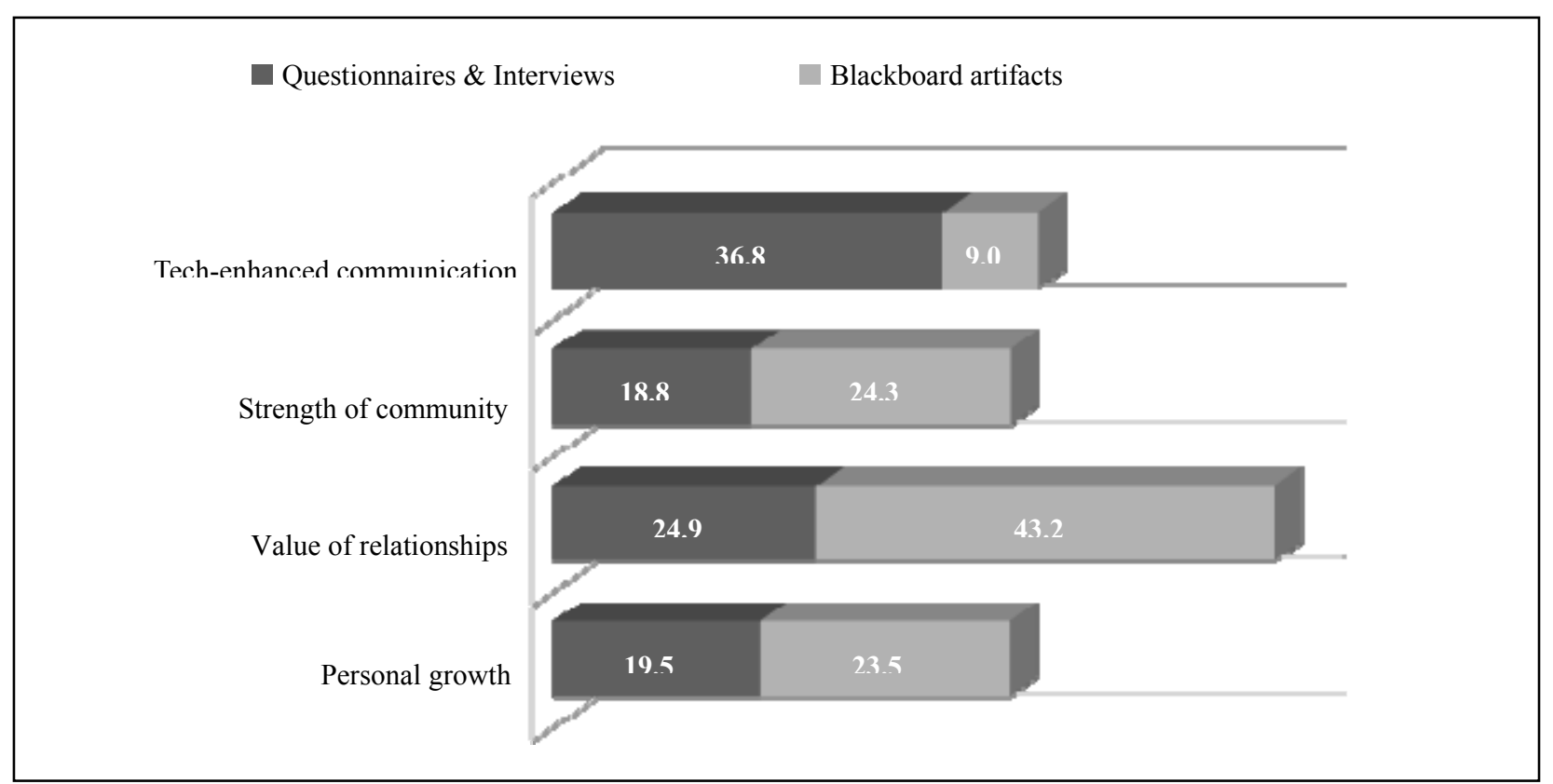

Figure 2. This figure illustrates the four central nodes and the corresponding data references by percentage.

In this case study, the service-learning students and their instructor benefitted from the reflective interactions through CMC technology as they built relationships. The instructor in this course addressed each of the four challenges to embedding and assessing reflective practice in this service-learning community (Larkin \& Beatson, 2014; M. E. Ryan \& M. Ryan, 2013). First, he established the visible framework for reflection to equip the students with the necessary skills. Secondly, he incorporated written reflective journals in Blackboard in order to provide support and supervision for the participants. Thirdly, he facilitated different forms of reflection through private journals, public discussion board postings, and face-to-face class discussions. Lastly, he used the relational model to teach and assess critical reflections.

Based on the findings from this study, the professor nurtured confidence in the students as they served and learned in the course (Tobias, 2010). As students developed, they incorporated their new knowledge and skills to their service sites, contributing to social change. The relationships that resulted from a unified community of practice and civically engaged students at their service sites, promoted life-long service, and meaningful learning (Cooper, 2013).

\section{Compliance With Ethical Standards}

This research received no specific grant from any funding agency in the public, commercial, or not-for-profit sectors. 
Conflict of interest: Author A declares that she has no conflict of interest. Author B declares that he has no conflict of interest.

Ethical approval: All procedures performed in studies involving human participants were in accordance with the ethical standards of the institutional and/or national research committee and with the 1964 Helsinki declaration and its later amendments or comparable ethical standards.

Ethical approval: This article does not contain any studies with animals performed by any of the authors.

Informed consent: Informed consent was obtained from all individual participants included in the study.

\section{References}

Al-Ansari, M. (2003). Using computer-mediated communication technology to facilitate students' intellectual and social interaction in a service-learning graduate course (Doctoral dissertation). Retrieved April 5, 2017, from ProQuest Dissertations \& Theses Global (Order No. 3104671).

Anderson, B., \& Simpson, M. (2007). Ethical issues in online education. Open Learning, 22(2), 129-138.

Becker, N. J. (2000). Service-learning in the curriculum: Preparing LIS students for the next millennium. Journal of Education for Library and Information Science, 41(4), 285-293.

Bleicher, R. E., Correia, M. G., \& Buchanan, M. (2006). Service-learning: Building commitment to becoming teachers. Retrieved from ERIC database (ED494939).

Bonk, C., \& King, K. (1998). Computer conferencing and collaborative writing tools: Starting a dialogue about student dialogue. In C. J. Bonk and K. S. King (Eds.), Electronic collaborators: Learning-centered technologies for literacy, apprenticeship, and discourse (pp. 3-23). Mahwah, NJ: Erlbaum.

Borman, G. D., Hewes, G. M., Overman, L. T., \& Brown, S. (2003). Comprehensive school reform and achievement: A meta-analysis. Review of Educational Research, 73(2), 125-230.

Calkins, L., \& Oxenhorn, A. (2005). Small moments: Personal narrative writing. Portsmouth, NH: Heinemann.

Cooper, L. Z. (2013). Student reflections on an LIS internship from a service-learning perspective supporting multiple learning theories. Journal of Education for Library \& Information Science, 54(4), 286-298.

Creswell, J. W. (2005). Educational research: Planning, conducting, and evaluating quantitative and qualitative research. Upper Saddle River, NJ: Pearson/Merrill Prentice Hall.

Davis, D. R. (2013). Cognitive and affective outcomes of short-term service-learning experiences: An exploratory study. International Journal for the Scholarship of Teaching \& Learning, 7, 1-15.

Dewey, J. (1938). Experience and education. New York, NY: Kappa Delta Pi.

Dubinsky, J. M. (2001). Service-learning and civic engagement: Bridging school and community through professional writing projects. Meeting paper presented at the Annual Meeting of the Warwick Writing Program, Department of English and Comparative Literacy Studies, University of Warwick. Retrieved May 1, 2017 from ERIC database. (ED459462).

Eisner, E. W. (1998). The enlightened eye: Qualitative inquiry and the enhancement of educational practice. Upper Saddle River, NJ: Merrill.

Farrell, M. (2014). Leadership reflections: Leadership development through service. Journal of Library Administration, 54(4), 308-317.

George, B. (2008). Leadership is authenticity, not style. In J. V. Gallos (Ed.), Business leadership (2nd ed., pp. 87-98). San Francisco, CA: John Wiley and Sons Inc.

Hawk, J. L. (2010). Service-learning: A vehicle to reflective thinking (Doctoral dissertation). Retrieved from ProQuest Dissertations \& Theses Global (Order No. 3421818).

Hoskins, M. (1995). Constructivist approaches for career counselors. Retrieved May 1, 2017, from ERIC database (ED401505).

Hughes, E. S., Bradford, J., \& Likens, C. (2018). Facilitating collaboration, communication, and critical thinking skills in physical therapy education through technology-enhanced instruction: A case study. Tech Trends, 62(3), 296-302.

Jacoby, B. (1999). Partnerships for service-learning. New Directions for Student Services, 87, 19-35.

Kahne, J., \& Westheimer, J. (1996). In service of what? The politics of service-learning. Phi Delta Kappan, 77(9), 593-600.

Kolb, D. A. (1983). Experiential learning: Experience as the source of learning and development. Upper Saddle River, NJ: Prentice-Hall.

Komives, S. R., Lucas, N., \& McMahon, T. R. (2013). Exploring leadership: For college students who want to make a difference (3rd ed.). San Francisco, CA: Jossey-Bass. 
Laird, D. (1985). Approaches to training and development. Reading, MA: Addison-Wesley.

Larkin, I., \& Beatson, A. (2014). Blended delivery and online assessment: Scaffolding student reflections in work-integrated learning. Marketing Education Review, 24(1), 9-14.

McDonald, M. A., Bowman, M., \& Brayko, K. (2013). Learning to see students: Opportunities to develop relational practices of teaching through community-based placements in teacher education. Teachers College Record, 115(4), 1-35.

Mills, S. (2001). Electronic journaling: Using the web-based, group journal for service-learning reflection. Michigan Journal of Community Service-Learning, 8(1), 27-35.

Murphy, P. (Ed.). (1999). Learners, learning, and assessment. London: Paul Chapman.

Nutefall, J. (2011). Why service-learning is important to librarians. Oregon Library Association Quarterly, 17(3), 16-21.

Ryan, M. E., \& Ryan, M. (2013). Theorising a model for teaching and assessing reflective learning in higher education. Higher Education Research and Development, 32(2), 244-257.

Schubert, W. (1995). Toward lives worth living and sharing: Historical perspective on curriculum coherence. In J. Beane (Ed.), Toward a coherent curriculum (pp. 146-157). Alexandria, VA: Association for Supervision and Curriculum Development.

Smirnova, M. M., Rebiazina, V. A., \& Khomich, S. G. (2017). When does innovation collaboration pay off? The role of relational learning and the timing of collaboration. Industrial Marketing Management. Retrieved April 22, 2018, from https://www.sciencedirect.com/science/article/abs/pii/S0019850117308234

Stake, R. (1995). The art of case research. Newbury Park, CA: Sage Publications.

Tobias, S. (2010). Generative learning theory, paradigm shifts, and constructivism in educational psychology: A tribute to Merl Wittrock. Educational Psychologist, 45(1), 51-54.

Vygotsky, L. S. (1978). Mind and society: The development of higher mental processes. Cambridge, MA: Harvard University Press.

Yin, R. (1994). Case study research: Design and methods (2nd ed.). Thousand Oaks, CA: Sage Publications.

Yin. R. (2009). Case study research: Design and methods (4th ed.). Thousand Oaks, CA: Sage Publications. 